\title{
Literature and Medicine: Twenty-Five Years Later
}

Peter Melville Logan*

Temple University

\section{Abstract}

An analysis of ten recent studies in Victorian literature and medicine examines the changes in the interdisciplinary field since G. S. Rousseau published an influential article on the topic in 1981.

Commenting on the state of research in literature and medicine in 1981, G. S. Rousseau, the scholar who has arguably had a larger effect on the field than any other, explained that, 'Literature and medicine ... is not a field that has claimed significant numbers of students' (406). He attributed the quiescence of the field and its subordinate status in literary criticism to the failure of scholars to comprehend the importance of the interconnection between the two terms:

the few students who have studied the interrelation of literature and medicine have either been unable to communicate their enthusiasm to readers or have failed to view the interrelation as ... profound, for there has been less scholarship about this subject tha[n] about any other area of traditional literary history or conventional history of science. (407)

In the roughly twenty-five years since then, the state of scholarship in this once anemic field has become robust and well-established. The journal Literature and Medicine began publishing in 1982, the year after Rousseau's assessment, and remains an important venue for new work in the field. In terms of sheer numbers, the contrast is particularly telling when considering the production of dissertations. In the five years immediately preceding Rousseau's article, there were five dissertations in literature with medical topics, or an average of one per year. ${ }^{1}$ Throughout the 1980s, that number was 6.5 per year. According to the most recent figures available (2001-05), we now generate 23 dissertations each year, claiming both literature and medicine as central topics. The current level of interest actually began in the early 1990s and has sustained itself for fifteen years. Many Literature Compass readers, presumably, are not big on math, but these figures show where the field stands in graduate schools today and 
clearly demonstrate the sea change since 1981. The current numbers further suggest that new research in literature and medicine (broadly defined) will remain vibrant for the next five years, as the younger cohort of scholars matures and begins to publish books based on their dissertations. Prediction beyond that requires a crystal ball, but what can be said with confidence is that the field is healthy today, in ways it was not in 1981, and that the current pace of publication is likely to continue for the immediate future.

How do we explain the transformation of the field that has taken place during the last twenty-five years? The newest studies on literature and medicine provide some of the answers. They also demonstrate the persistence of several problems Rousseau mentioned. In this essay, I discuss ten books on Victorian literature and medicine published since 2003 and consider how they construct the relationship between the two fields. ${ }^{2}$ They cover a wide range of topics. Three focus on gender: Swenson presents a new take on the ever-popular exploration of literary representations of medical practitioners, Archimedes revisits the medicalization of women in the nineteenth century, and Smith looks at masculinity and Gothicism in the fin de siècle. Like Smith, Stoddard Holmes takes up genre conventions crossing the literature/medicine divide, in her study of melodrama and disability. Hers is one of two studies of physical dysfunction: Frawley examines narratives of Victorian invalids. One book focuses on a scientific epistemology: Caldwell examines natural theology, medicine, and early nineteenth-century literature. Three others connect broad medical concepts to literary tropes: Gordon discusses physiology and literature, Torgerson looks at disease in the writing of the Brontës, and Christensen surveys the rhetoric of contagion in European literature. Finally, one study is devoted to a particular bodily organ, Blair's book on the rhetoric of the heart in medicine and poetry. As a whole this new body of work suggests that many critics have found ways to communicate the importance of the combined field and thus supplied the missing desideratum of 'profundity'. Some locate that significance directly in the historical interplay between texts in literature and medicine; at other times significance resides in moral or ethical messages identified with the older works. In some cases reciprocity between literature and medicine is entirely missing, but examples of this are relatively few.

Considered in isolation, literature and medicine appears to be a particularly popular field, and, while there is some truth in this, this impression is exaggerated. Interdisciplinary studies in the humanities have become far more common since the 1970s. Rohan McWilliam, discussing the phenomenon in history departments, calls it the 'interdisciplinary tide of the post-1980 generation' (17). Many boats have floated with that rising tide, and literature and medicine is one of them. There are more studies in literature and medicine than there were twenty-five years ago, but there are more studies in general today that cross disciplinary boundaries, 
borrowing from sociology, anthropology, philosophy, as well as the distinct histories of law, politics, popular culture, philosophy, medicine, and the many other elements that fit into the commanding interest in studies of culture. Such studies were unusual in 1981, and they were also under siege. In literature departments, they were opposed by the New Criticism, an older school that often viewed literature as if in a bottle, safely sealed off from the social concerns of feminist, materialist, and historicist criticism. In the history of medicine, opposition came from the 'internalists', who adopted a positivist narrative of the march of ideas largely isolated from the social context examined by the 'externalists'. Social critics eventually dominated both disciplines, and that shift has been favorable to interdisciplinary work in general, including studies of literature and medicine.

With this caveat in mind, there are also reasons to think that studies of literature and medicine have been one of the larger beneficiaries of the change in the humanities. The shift toward more contextualized interpretations of literature led to studies that highlighted the importance of the body as a site for naturalizing received ideas about social difference. Within Victorian studies, Mary Poovey's early work was critical, along with that of historians Ludmilla Jordanova and Thomas Laqueur. ${ }^{3}$ With literary critics interrogating the categories of gender, race, class, sexuality, 'perversion', and disability, the body took on a new significance. Medical discourse was particularly pertinent to these concerns because it offered a textual source for tracing the mutation of cultural beliefs into embodied concepts that were called 'natural'.

McWilliam attributes the increased use of inter- and multidisciplinary analytical procedures to the linguistic turn of the 1980s and the related development of poststructuralism, which 'swept across the Humanities raising issues about the interpretation and the deconstruction of texts' (11). Literary studies and philosophy served as launching pads for this new movement. Feminist, New Historicist, and Cultural Materialist critics demonstrated the extent to which primary documents previously reserved to history departments were amenable to modes of literary analysis normally practiced on fiction and poetry: explorations of metaphor, style, rhetoric, and narrative structure could generate new understandings of these documents, as Gillian Beer successfully demonstrated.

It is not my purpose here to review the broader history of the transformations that took place in the two disciplines during the linguistic turn or the cultural turn that followed it. I merely want to show the extent to which the solution to Rousseau's complaints - about the lack of profundity in studies of literature and medicine prior to 1980 and about the central importance of reciprocity - lay in the poststructuralist methods adopted by writers in the combined field after the 1980s. It was not, in other words, the disparity between literature and medicine that caused the problem in 1981 so much as the dearth of methodological tools for exploring their similarities in the era of literary formalism and internalist 
historiography. The emergence of those tools and their introduction into the graduate curricula led to the trebling of dissertations on literature and medicine in the 1990s. The humanities embraced novel ideas following from Saussurean linguistics, Derridean deconstruction, and the Foucauldian analysis of power, and each offered new models for combining disparate discourses into a significant whole by largely blurring the generic distinctions between them and applying unified methods of analysis to both. ${ }^{4}$

While most volumes in the current group of works succeed in terms of identifying a substantial significance in the correlation, several do not. John Gordon's Physiology and the Literary Imagination: Romantic to Modern best illustrates the problem inherent to a lack of engagement with medical writing and the resultant unidirectional model of influence, in which medical writers initiate concepts that literary writers adopt. Gordon considers one Romantic writer, William Wordsworth; three Modern, T. S. Eliot, Dylan Thomas, Sylvia Plath; and two Victorians, Charles Dickens and Gerard Manley Hopkins. The latter's 'idea of the physiological basis of cerebration - including the kind that made for inspired poetry - might be said to have become possible' due to Victorian ideas about electrical energy (115). His discussion of Dickens is equally speculative, as he argues for the writer's changing perception of human interiority, from one based on blood flow to a neurological model. Gordon may be right, but the evidence presented here is unconvincing. These are interesting possibilities, carefully stated and highly readable, but ultimately little is at stake beyond antiquarian curiosity in the discussions of Dickens and Hopkins; the information adds to what we know (possibly), but it does not change how we interpret the works or their reception at the time. Gordon explains that his goal is 'to trace how . . received notions of medical fact held by certain representative writers play out in these writers' delineations' (1). He calls this 'history inside-out', and explains that his process is

to seek for the likely origins of those assumptions from among the medical theories and practices current at the time; and to then return to the author's writings to see if I can isolate and track what has been made of what was in the air. (1)

Missing here is a better sense of why these aerial concepts or their reworking by novelists and poets matter. Rather than reciprocity, medicine acts and literature reacts, and in that one-way flow of ideas, the problem of profundity that Rousseau noticed reemerges.

The other work that falls into the unidirectional trap is Beth Torgerson's Reading the Brontë Body: Disease, Desire, and the Constraints of Culture. Like four others in the current group (Caldwell, Swenson, Blair, Archimedes), this study originated as a dissertation. It argues that the Brontë sisters were intimately familiar with sickness and looks at how illness provides them with unique ways to critique gender and class constraints inherent in Victorian culture' (3). She takes up this project in four chapters, discussing 
Anne Brontë and alcoholism, the place of cholera in Charlotte Brontë's Shirley, hysteria in Villette, and Emily Brontë's exploration of disease as a response to patriarchy in Wuthering Heights. A conclusion notes the differences among the three sisters. Each chapter reviews the history of the disease by summarizing the interpretations of medical historians; medical texts as such are not considered. Like Gordon, this study focuses exclusively on literature's reworking of medical concepts, although Torgerson has a significantly different reason: 'this study aims to contribute to a deeper understanding of the ways in which Victorian ideas of the body ... inform literary texts of the time period' and provide 'powerful tools for a cultural analysis of literary texts' (17). As scholarship in literature and medicine matures, this basic claim that medical thinking actually has a cultural register becomes less remarkable and more derivative; it is a starting point for analysis but no longer a discovery in its own right. More original is Torgerson's use of medical anthropology. There is certainly potential here for future work, but here it produces ahistorical assumptions that contradict the book's interest in medical history. Torgerson uses it to reduce human physicality to a somatic shadow of psychology: "the body carries wounds, the signs of conflict, when there are discrepancies between what the self desires and what the culture allows' (5). All cultures seem to have the same psychology: 'Wherever illness exists, it signifies tensions with the life or within the text' (8). Given the universalism of these claims, the role of medical history is reduced to annotation, as in Gordon. To Torgerson's credit, she is straightforward in her assumptions, and her readings of individual novels are intelligent and attentive to detail.

Kristine Swenson's Medical Women and Victorian Fiction has the advantage over Gordon and Torgerson of discussing little-studied novels. It focuses on late-Victorian fiction featuring female medical practitioners (reformed nurses and female doctors); scholars in the New Woman novel, in particular, will benefit from her work. Rather than taking up disease constructs, Swenson concentrates on 'the cultural intersections of fiction, feminism, and medicine' by looking at the institutional context of woman in medicine (2). In literature, she examines 'how Victorian fiction figured the medical woman', working with the sensation novel, New Woman novel, and adventure fiction of $\mathrm{H}$. Rider Haggard, Rudyard Kipling, and Hilda Gregg (3). The results may surprise few Victorianists; the study uses a familiar paradigm of gender subversion and containment that quickly becomes predictable. Additionally, like Torgerson, the writer finds something surprising in the basic fact of an ideological register to the discourse on nursing (9). But there also is much to like in this original study. Swenson engages primary medical texts, like Gregg's essay on 'Prostitution' and Florence Nightingale's Notes on Nursing, giving them brief but direct interpretations. The study also recognizes the possibility of a literary influence on medicine, arguing that Elizabeth Gaskell's Ruth influenced Nightingale's concept of nursing (16-20). Evidence is largely conjectural, 
but Swenson's speculation runs from literature to medical practice, as well as medicine to literature, and that acknowledgment of reciprocity provides a substantive justification for examining both fields.

Sondra M. Archimedes relies more extensively on Victorian medical writing, in Gendered Pathologies: The Female Body and Biomedical Discourse in the Nineteenth-Century English Novel, giving this study a welcome grounding in the language of Victorian medicine. The passages are used strictly to document historical ideas, without considering style or rhetoric, but they are well selected. Archimedes makes no claims about the effects of literature on medicine, but she views both discourses as subject to and mutually reinforcing the same cultural beliefs about women. In an illuminating argument, the study focuses on the homology between the physical body and the social body in Victorian fiction, with separate chapters on Dickens, Haggard, and Thomas Hardy. Gendered Pathologies is particularly concerned with the female body and argues that 'the social body is an extension of the female body, literally and figuratively linked to its referent through tropes of reproductive peril' (4). Non-reproductive female bodies limit the ability of populations to reproduce and so endanger the social body; thus, non-reproductive women are pathologized in medical writing. Fiction displaces this social problem onto the bodies of deviant women, a point she demonstrates convincingly in her study of Dickens's Hard Times.

Other works in the list add a further layer of interest to their analyses by interrogating medical writing with the same attention to language they employ in analyzing literature. Not coincidentally, these studies generally take a more nuanced stance toward the interrelationship between literature and medicine, seeing them as engaged in an ongoing intercourse of mutual borrowings. Four of the current group best illustrate the way in which reciprocity supplies an essential justification for examining the two discourses in tandem, without reducing one of the other to subordinate status.

In Fictions of Affliction: Physical Disability in Victorian Culture, Martha Stoddard Holmes reviews images of female disability in an impressive array of novels and non-fiction works from the mid- to late century, including works by Henry Mahew, Wilkie Collins, Dickens, Charlotte Mary Yonge, and Dinah Maria Mulock Craik. As in Archimedes, the female body represents a reproductive threat, but this time in the opposite direction: the fear that reproduction will transmit disability to a new generation. Thus it was 'interesting to imagine a disabled woman as a sexual being, but far too alarming to allow her to reproduce' (7). A useful appendix includes a list of disabled characters in nineteenth-century fiction. The strength of the study is its treatment of melodrama as a genre with a special connection to representations of disability as a condition of exaggerated emotions. Analyzing a series of 1825 lectures on blindness published in the Lancet, she identifies the influence of melodramatic 
rhetoric in medical writing on the single most prevalent condition associated at the time with disability; thus 'Literary and nonliterary works, similar in their melodramatic rhetorics of affliction, worked in complementary ways with the concept of disability as a social identity and social problem' (30). In training audiences 'how to feel about disability', novels were a significant source of cultural values (32).

Invalidism is related to the topic of disability, though whether or not it was a genuine condition is one of the questions take up by Maria $\mathrm{H}$. Frawley, in Invalidism and Identity in Nineteenth-Century Britain. This study is unique among this group for its singular focus on the patient's perspective, arguing that the invalid narrative constitutes a subgenre of its own, rooted in the knowledge produced by illness. Following an introduction, it structures its topic thematically, looking at narratives of hypochondriacs, memoirs of invalids who travel for their health, the positive view of suffering found in Christian invalid narratives, and memoirs about life in the sickroom. It devotes extended discussion to three writers: Edward Bulwer-Lytton, Harriet Martineau, and John Addington Symonds. Most of the study is given over to briefer encounters. In addition to its account of invalid autobiography, Frawley's book is valuable for locating Victorian representations of the invalid. She scours periodical literature, advertisements, and fiction for examples. Medical writing as such is largely absent, as Frawley relies on secondary sources for the history of medicine. But given the study's focus on the sufferer, the peripheral nature of medical writing does not elide reciprocity between literature and medicine; instead it takes the form of an interaction between the conventions of the literary genre and the patient's experience. As a study in the cultural history of illness, Invalidism and Identity works well, and its claims about the invalid narrative are an original contribution to the study of life writing.

In terms of articulating a critical interaction between literature and medicine, one of the most successful of the ten current works is also the only one centrally devoted to poetry, Kirstie Blair's Victorian Poetry and the Culture of the Heart. Blair concentrates on the early to mid-Victorian period, beginning with insightful chapters on medical writing about the heart, she traces the association in medicine of writing with heart disease and explores the imagined affective relationship between verbal rhythm and the pulse. She further explores these topics in chapters on the three major poets of the study: Elizabeth Barrett Browning, Matthew Arnold, and Alfred Tennyson. The connection between verbal rhythm and the pulse makes a compelling case for the specific value of investigating medicine and the genre of poetry, rather than prose. While Blair's claims about the rhythmic onomatopoeia of verse become at times repetitive, the principle of correlation works well. In an original interpretation of medical texts, Blair demonstrates that medical authors routinely incorporated poetic passages on the heart into their monographs; they were broadly familiar with contemporaneous literary representations of the heart, and 
these literary conventions re-emerge in the rhetoric they used to describe heart conditions. Thus part of her analysis demonstrates how 'nineteenthcentury physiologists found in the heart the qualities which poetry had already taught them to look for' (28). The more familiar, opposite interaction occurred as well. Doctors associated writing with weak hearts, and poets like Henry Hallam tended to see heart conditions as a badge of pride a proof of membership in the literary sphere - and utilized it in their poetry.

Blair highlights reciprocity, rather than apportioning primacy to either literature or medicine as the source of ideas about the cardiac organ: "both poets and doctors were engaged in a mutual exchange of ideas about the heart which helped to shape a "culture of the heart" specific to Victorian Britain' (18). This is precisely the move away from unidirectional 'influence' that Rousseau advocated as an anodyne for the field's anemia. 'Without some reciprocity', he argued, 'from literature to medicine as well as medicine to literature - there is neither a field nor its state to survey' (424). Twentyfive years later, there is such a field, and within it studies like Blair's have successfully demonstrated the importance of interpretive reciprocity and the potential it offers to critics who use it well.

Like Blair, Andrew Smith is unusually successful at finding significance in the interplay of the two forms of writing. The only study to focus predominantly on sexuality, Victorian Demons: Medicine, Masculinity, and the Gothic at the Fin-de-Siècle argues that the crisis in late century models of masculinity stemmed from medicine's new pathologization of the male body, most notably in the claims about degeneration and syphilis. His main subjects are John Merrick (who was called 'The Elephant Man'), the Whitechapel murders, Arthur Conan Doyle, Robert Lewis Stevenson, Bram Stoker, and Oscar Wilde. Smith excels at reading medical and social science texts with careful attention to their literary tropes; his particular focus is on the deployment of literary conventions of Gothicism in the rhetoric of Frederick Treves's medical account of Merrick and in the journalistic accounts of the Whitechapel murders. Victorian Demons also examines Gothicism in Max Nordau's discussion of syphilis (in Degeneration) and two medical texts on the subject from the late century, whose 'use of language and metaphor functions in much the same way' as in literary texts (95-6). These receive detailed and rewarding close readings. Smith concludes that the two medical texts 'indicate a desire to both discuss the dangers of apparently normative middle-class male sexual conduct, and an attempt to conceal such conduct', supplying us with a level of historical nuance often missing from literary criticism (115).

Smith and Blair's works excel as models of the critical value offered by the reciprocal study of literature and medicine. Inevitably, new approaches raise new questions; in this case, the successful blurring of discursive boundaries poses a challenge to the definition of 'literature and medicine'. Some literary critics, like Poovey, have produced original work in the 
history of medicine by interpreting medical texts. But others, as we have seen, continue to rely entirely on the work of historians to establish their claims about medical history, ignoring the actual language of medicine. There also exists a wide variation in the proportionality of literature and medicine as separate discourses in studies of the combined field. Some of the studies under examination here give medical writing a great deal of attention, while others keep it at arm's length. All ten studies qualify, because each discusses literary writing in connection with medical issues, but reciprocity raises the issue of what, exactly, counts as literature? Specifically, does a literary critic's analysis of medical writing qualify as a study in 'literature and medicine', even though there may be no 'literature' under consideration? Because the application of literary methods of analysis, such as tracing figurative language and rhetorical tropes, treats medical discourse as literature, I think the answer has to be 'yes'. But in that case, 'literature' is being redefined as a mode of interpretation rather than a mode of writing, so that 'literature and medicine' refers to the employment of a disciplinary methodology unique to literature departments. What happens to historical work in the field?

Professional historians today make more use of literary texts and of the scholarship generated by literature-based studies than in the past. Two recent examples are Hilary Marland's Dangerous Motherhood: Insanity and Childbirth in Victorian Britain, an important history of puerperal insanity, and Akihito Suzuki's Madness at Home: The Psychiatrist, the Patient, and the Family in England, 1820-1860, an equally significant history of the role of the family in the treatment of insanity. Both works treat studies by literature scholars seriously, which is a welcome change from the 1980s, but neither of them has the extended engagement with literature as a body of writing that English scholars (and presumably the readers of Literature Compass) are typically interested in exploring. Few medical historians engage in literary exegesis, a situation that is as true today as it was in 1981 (Rousseau 409). The historian E. P. Thompson was able to write important studies in both fields, but such cross-disciplinary expertise has always been the exception. Anecdotal evidence further supports the view that literature remains an esoteric concern in history departments. At the 2007 conference of the American Association for the History of Medicine, the leading professional organization in the field, I was the only presenter from a literature department, and my presentation was on medical writing, rather than fiction or poetry.

Marland and Suzuki have produced significant new studies in the history of medicine, studies that literature-based scholars will want to use in their own work. Do critical studies of literature and medicine bear a similar necessity for historians? In a 2003 review of new books in literature and medicine, the medical historian Roger Cooter suggests that the selected literature-based studies of Victorian medical concepts were contributing little to the history of medicine. While acknowledging that 'some such 
tendency is apparent', it would be 'unwise to conclude . . that the literature turn has infiltrated conventional history of medicine' (516). His analysis is largely unable, or unwilling, to ford the disciplinary moat he perceives between 'literary-discursive and historical approaches', as if representation and history were distant cousins and that the study of one could safely exist without an understanding of the other (516). Cooter's remarks are a fair illustration of a continuing problem, one that Rousseau identified twenty-five years ago:

medical historians have been reluctant to concede that language, even when applied to situations in which patients require sympathy or when surveyed in relation to the placebo concept, plays a significant role in medical theory or practice. (423)

Language matters because it defines how the historical real is perceived and acted on. But Cooter generally dislikes 'the analysis of discursive meanings', complaining - in a wonderful display of his own command of rhetorical effect - about its 'precious poetics, its jargon on textualization, signs, signifiers . . . and its literary tactics of metaphor, metonymics, synecdoche, analogy, defamiliarization, and, above all, close reading' (520).

It would be easy to dismiss Cooter's argument as simply biased, but it would be a mistake. He is not blind to the value attention to language brings to the history of medicine: he praises Ian Burney's study of the coroner's inquest, Bodies of Evidence: Medicine and the Politics of the English Inquest, 1830-1926, for its successful combination of history with an attention to representational issues. Indeed, if the topic of this review were 'language and medicine', rather than 'literature and medicine', Burney's book would find a welcome place within it. Ultimately Cooter's objection is less to the tools of literary analysis as such and more to the ahistorical uses to which they are sometimes put, and in this regard it is difficult to disagree with him. When literary critics make historical arguments, they are willing to accept a higher degree of speculation and generality than is allowable in the discipline of history: there, nuanced arguments about historical change are the equivalent of close-reading techniques in literature. To historians, claims about the existence of undifferentiated, monolithic historical forces that supposedly operate everywhere and explain everything are about as convincing as bad plot summary in a student paper. Precision is everything, and when it comes to historical claims, literary critics too often embrace the kind of overarching meta-narrative that current historians reject.

Several of the current studies demonstrate this casual approach to historical causality. In addition to Gordon's idiosyncratic 'history inside-out', we have Allan Conrad Christensen's personal take on the subject, in NineteenthCentury Narratives of Contagion: 'Our Feverish Contact'. Christensen briefly reviews the major nineteenth-century medical theories of contagion before 
moving into his main topic, the centrality of contagion as a metaphor in nineteenth-century European culture. This is a historical claim, and it may even be true, but the evidence presented here comes exclusively from his own readings of selected novels, viewed as 'versions and parts of a single master text' within the 'European Zeitgeist' (9). The novels are by Gaskell, Dickens, Charles Kingsley, Bulwer-Lytton, Harrison Ainsworth, Émile Zola, and two Italian writers, Giovanni Ruffini and Allesandro Manzoni. Basic primary sources on contagion, like Edwin Chadwick's Sanitary Report (1842), are missing and seem to bear little relation to Christensen's idea of contagion: 'Any situation that demonstrates the largely involuntary susceptibility of a human being to influences coming from without may imply the ubiquitous contagious mechanism' (19). Thus contagion is the fictional representation of different involuntary influences that 'travel and spread from individual to individual, imposing themselves or meeting with resistance' (9). The study argues that these forces play out on 'a common field of contagion ... which can be called history as well' (9). This is, to say the least, a unique definition, and to his credit, Christenson acknowledges it.

The significance of the term 'history' that my own text proposes is obviously different from that of standard history books. It refers less to particular historical facts and political events (which are only understood to be occurring in the background) than to the climate of the cultural environment. (10)

Christensen's terms, 'climate' and 'environment', are synonyms that can be used interchangeably with the third term, 'culture', so what he is actually saying is that history is the study of 'the culture of the cultural culture'. I am not sure what the point is here, but that is exactly the problem we find when literary critics adopt convenient, eccentric definitions for the object of historical analysis, and use them to make broad claims about the past. With such an approach to history, historical claims collapse into a Rorschach moment of impressionism, particularly when basing those claims solely on the literary works. This casual approach to documentation - I see it in fiction, so it must be real history - drives historians like Cotter up the wall. It should affect everyone that way who values a genuine interdisciplinarity between Victorian literature and medicine. One can complain that Cooter's approach to the power of language is benighted, but literary critics that make such reductive historical claims are no less guilty of blindness in reducing historiography to wish fulfillment. This practice alone can account for the underwhelming reaction of historians of medicine to many literary studies of medical topics.

Not all work in literature and medicine relies on the history of medicine as its point of reference. The technical curriculum of medical schools has given little space to the historical and philosophical aspects of medical practice. The most prominent professional response to this situation has been the development of professional journals and degree programs in 
bioethics, the study of moral issues in health practice and research. Other journals and less formal groups address this deficit by drawing on the representations of sickness in literature and art, and it is within this branch of the medical humanities that literature and medicine also come together. Medical Humanities is a British journal for health professionals that regularly includes short essays on medical themes in literature, mostly written by and for health professions. It describes itself as 'an interdisciplinary exploration of how humanities disciplines can engage and illuminate the nature, goals, and practice of medicine'. ${ }^{5}$ This orientation toward current medical practice is the rule rather than the exception. Felice Aull, who runs the large Medical Humanities site at the New York School of Medicine, explains that they focus on the humanities, social sciences, and the arts, in terms of 'their application to medical education and practice', because they help 'to develop and nurture skills ... that are essential for humane medical care'. The site houses an encyclopedic collection of annotations summarizing the medical aspects of individual works of literature, which can prove helpful to scholars looking to compile a bibliography of literary texts featuring doctors or specific diseases. However, this branch of medical humanities is not yet a research field, like bioethics, devoted to generating new knowledge; rather, it is an educational movement to promote familiarity with medical themes in art and literature to the existing medical community, hopefully improving the quality of their practice.

An interest in medical humanities sits uneasily within one of the studies under consideration here, Janis McLarren Caldwell's Literature and Medicine in Nineteenth-Century Britain: From Mary Shelley to George Eliot. The book's title promises a systematic overview of the connection between literature and medicine in the nineteenth century. Rick Rylance managed to deliver on such a promise, in Victorian Psychology and British Culture, 18501880 , by producing a complex perspective on the topic, laying out the different treatment psychology received in religious, philosophical, biological, and medical discourse, and explaining how the competing accounts interacted. Caldwell's focus is more specialized, and the study never pretends to the kind of comprehensiveness promised by its title. The volume explores the interpretive strategy of 'Romantic materialism' in the nineteenth-century discourses of literature, science, and medicine before Charles Darwin's Origin of Species (1859). Following an introduction to the method, Caldwell deploys it in separate chapters. She describes two distinct models of sympathy in her discussion of Shelley's Frankenstein. Her chapter on Thomas Carlyle's Sartor Resartus discusses Richard Owen, as well, and sees in him a naturalist version of Carlyle's natural supernaturalism. In addition to chapters on Wuthering Heights, Jane Eyre, and Darwin's Autobiography, the volume takes up the cause once more of the physician Lydgate, in Eliot's Middlemarch.

Caldwell is interested in the how accounts of nature at the time viewed the physical world through a scriptural lens, interpreting it as one of God's 
'two books', the book of nature and the book of scripture; a priori, nature held evidence of a hidden, providential design. In William Paley's theory of natural theology, and in William Whewell's confutations of positivism and evolution, there was a consistent oscillation between nature and the scripture in these provisional attempts to reconcile science to religion. By 'Romantic materialism', Caldwell refers to a method of interpreting the physical world through a synthesis of objective observations with subjective experience, which correlates with the oscillation between the 'two books' found in natural theology. The study argues that literature and medicine were similarly influenced by the doctrine, one that comes to a halt with the publication of Origin of Species. The interpretive framework at the center of the study is the hermeneutic circle of Friedrich Schleiermacher, the German Romantic philosopher of religion. He described a circular pattern of interpretation that looked at the part in relation to the whole, while considering the whole as intelligible only in terms of its parts. From part to whole to part to whole to ... the hermeneutic circle is an endless process of interpretation. Caldwell broadens the circle, perhaps too much, to include any two contrasting terms, seeing them in an endless 'productive conversation', while pursuing tentative conclusions at the point where the two terms 'agreed with one another' $(20,19)$. Thus Caldwell prioritizes a dialectic of 'shuttling back and forth between contrasting ways of reading in search of a provisional interpretation' (20). In this manner, her study claims to 'reveal the legacy of Romantic hermeneutics for literary study in our own time' (21).

Caldwell incorporates original writing, largely from natural history, drawing attention to the writer's language, as in the chapter on Darwin's Autobiography. Because of the book's focus on natural history, medical writing is little in evidence, but there is an interesting use of archival materials in considering the format of case histories in the 1840s. ${ }^{6}$ Caldwell's book takes a turn toward medical humanities in this discussion, when she equates the two parts of the case history, patient narrative and medical observation, with the hermeneutic of Romantic materialism, and begins an impassioned appeal to current physicians and medical educators: 'we should be working harder at practical education in sympathetic concern' (154). Medical students need be taught to circle 'between empathy and respectful distance from a patient' (154). One can sympathize with this goal while also recognizing that Caldwell's shift away from an audience of literary critics to address current practitioners signals a conflict between the study's historical claims and its contemporary ethical imperatives, a problem that also appears in Torgerson's study. The conflict shows up throughout Literature and Medicine in close readings of literary texts that too often rely on impressionism instead of evidence. It will surprise many readers to learn, for example, that Lydgate introduced Middlemarch provincials 'gradually... every so gently, to the idea of the autopsy' (162). The author's efforts to make the selected texts (Frankenstein and 
Middlemarch in particular) fit her contemporary ethical concerns can seem like forcing a square peg into a round hole.

The study's orientation toward the present leads to a second methodological weakness. No where do we find that literature influenced medicine. Notwithstanding Caldwell's preoccupation with bidirectional interpretation, the author practices a wholly unidirectional model of influence, flowing from the philosophy of science and medicine to literature. This limits the significance of literature in its partnership with medical writing, sacrificing the kind of essential interaction that Blair, Smith, and Stoddard Holmes exemplify. While this limiting factor exists in several other studies covered here, its absence from a study that prioritizes the Romantic materialist project of oscillation between competing perspectives is a particularly significant missed opportunity.

Rousseau noted the high hurdle of additional work required to tackle literature and medicine in a substantive way; scholars have to master 'the considerable knowledge required to write about the interaction' between the two fields, and that requirement to do, in essence, double duty poses a very real impediment (407). In addition to facts, one has to learn two conflicting methodologies. Literary criticism relies far more on cultural synecdoche than historians do; some of the current crop of studies use a single work of literature (or sometimes of medicine) to assert the existence of a specific cultural pattern in the Victorian era. Our training teaches us to look for the wealth of information contained in small bodies of discourse; this same training leads us to focus more on synchronic problems than diachronic questions of historical change, as historians do. This is a cartoonish oversimplification, but my point is heuristic: if 'culture' is a text, we want to know everything about how it works; historians want to know why it changes. Given the absence of training for literature students in historiography and our disciplinary privileging of synecdoche, this emphasis on the synchronic is unlikely to disappear; thus, overcoming this disciplinary 'hurdle' remains a problem. ${ }^{7}$

The broader picture of literature and medicine that emerges in the current crop of studies, however, is not one that condemns us to disciplinary isolation. Certainly they illustrate the persistence of some of the problems Rousseau identified. However, while not quite on the road to marriage, at least the parties are talking. Even though Cooter criticizes them, he has to include books by literary scholars in his overview of the field, and that in itself is a significant development. Besides the quantitative difference between studies since 1981, qualitative changes have, in fact, brought the two disciplines into a more productive conversation. Historians are become more cognizant of language. Literary scholars, notwithstanding their problems in historiography, are more adept at interpreting primary historical documents. Stoddard Holmes, Smith, and Blair all utilize closereading skills, perform careful rhetorical analysis, and consider problems of literary form in their analyses of medical texts. Most of these primary 
texts have never received this degree of scrutiny before, and those analyses reveal a refreshing level of complexity in medical books which, while valued by historians for their ideas, continue to reveal more nuanced aspects of those ideas than historical methods alone have so far been able to identify.

Literature and medicine may by unable to reconcile the methodological differences between historiography and literary criticism, but they come together in a shared conversation about the same texts. This joint interest has little to do with historians discovering new value in fiction and poetry. Insofar as 'literature and medicine' refers to studies of literary and medical works, the joint term describes a phenomenon that almost exists exclusively within literature departments. But if 'literature and medicine' instead refers to two different disciplines with a shared interest in medical writing, then it does become meaningful as a descriptive term for a genuinely interdisciplinary field, and one which has only come into existence in the past twenty-five years. A better term for this interdisciplinary field is 'language and medicine', and I believe that by reconsidering our terms, we can finally begin to move away from an interdisciplinary field that, paradoxically, exists solely within literature departments, and reconceptualize a field in which close reading and historical change can productively come together.

\section{Short Biography}

Peter Melville Logan is currently writing on the use of fiction in Victorian psychiatric discourse and psychiatric discourse in Victorian fiction. He is the author of Victorian Fetishism: Intellectuals and Primitives (Albany, NY: State University of New York Press, 2009) and Nerves and Narratives: $A$ Cultural History of Hysteria in Nineteenth-Century British Prose (Berkeley, CA: University of California Press, 1997). He is also Editor of the Blackwell Encyclopedia of the Novel, scheduled for publication in 2009, and Associate Professor of English at Temple University.

\section{Notes}

^ Correspondence address: 1114 W. Berks Street, Philadelphia, PA 19122-6090, United States. Email: peter.logan@temple.edu.

${ }^{1}$ The total figures for dissertations produced in each five calendar years are as follows: 198185, 32; 1986-90, 35; 1991-95, 112; 1996-2000, 132; 2001-05, 115. ProQuest, search: title and abstract 'medicine', subject 'literature', date range '01/01/1976 to $12 / 31 / 1980$ ', '01/01/2001 to $12 / 31 / 2006$ '.

${ }^{2}$ Two more studies appeared too late for inclusion in this review, though both are important contributions: Linda M. Austin, Nostalgia in Transition, 1780-191, and Nicholas Dames, The Physiology of the Novel: Reading, Neural Science, and the Form of Victorian Fiction.

${ }^{3}$ Poovey's article reappeared two years later in her field-changing book.

${ }^{4}$ Gallagher and Laqueur's anthology from the late 1980s best exemplifies the trend. Many studies during the 1990s reflected similar priorities: see Gilbert, Logan, Rothfield, Small, and Vrettos. 
${ }^{5}$ Medical Humanities is published twice yearly by the Institute of Medical Ethics of the British Medical Association.

${ }^{6}$ On case histories, see Caldwell, Literature and Medicine 144-50.

${ }^{7}$ This is by no means an original point. McWilliam suggests that 'too much might be expected of interdisciplinarity' (21). See also Fish.

\section{Works Cited}

Archimedes, Sondra M. Gendered Pathologies: The Female Body and Biomedical Discourse in the Nineteenth-Century English Novel. Literary Criticism and Cultural Theory. New York, NY: Routledge, 2005.

Aull, Felice. 'Mission Statement'. Medical Humanities. n.d. 11 September $2007<$ http://medhum. med.nyu.edu/>.

Austin, Linda M. Nostalgia in Transition, 1780-1917. Victorian Literature and Culture. Charlottesville, VA: U of Virginia P, 2007.

Beer, Gillian. Darwin's Plots: Evolutionary Narrative in Darwin, George Eliot, and Nineteenth-Century Fiction. London: Routledge, 1983.

Blair, Kirstie. Victorian Poetry and the Culture of the Heart. New York, NY: Oxford UP, 2006.

Burney, Ian A. Bodies of Evidence: Medicine and the Politics of the English Inquest, 1830-1926. Baltimore, MD: Johns Hopkins UP, 2000.

Caldwell, Janis McLarren. Literature and Medicine in Nineteenth-Century Britain: From Mary Shelley to George Eliot. Cambridge Studies in Nineteenth-Century Literature and Culture 46. Cambridge: Cambridge UP, 2004.

Christensen, Allan Conrad. Nineteenth-Century Narratives of Contagion: 'Our Feverish Contact'. Routledge Studies in Nineteenth-Century Literature 1. London: Routledge, 2005.

Cooter, Roger. 'The Traffic in Victorian Bodies: Medicine, Literature, and History'. Victorian Studies: An Interdisciplinary Journal of Social, Political, and Cultural Studies 45.3 (2003): 513-27.

Dames, Nicholas. The Physiology of the Novel: Reading, Neural Science, and the Form of Victorian Fiction. Oxford: Oxford UP, 2007.

Fish, Stanley. 'Being Interdisciplinary Is So Very Hard to Do'. Profession (1989): 15-22.

Frawley, Maria H. Invalidism and Identity in Nineteenth-Century Britain. Chicago, IL: University of Chicago Press, 2004.

Gallagher, Catherine and Thomas Walter Laqueur, eds. The Making of the Modern Body: Sexuality and Society in the Nineteenth Century. Berkeley, CA: U of California P, 1987.

Gilbert, Pamela K. Disease, Desire, and the Body in Victorian Women's Popular Novels. New York, NY: Cambridge UP, 1997.

Gordon, John. Physiology and the Literary Imagination: Romantic to Modern. Gainesville, FL: UP of Florida, 2003.

Institute of Medical Ethics. Medical Humanities 33.1 (2007): back cover.

Jordanova, Ludmilla. Sexual Visions: Images of Gender in Science and Medicine between the Eighteenth and Twentieth Centuries. Science and Literature. Madison: U of Wisconsin P, 1989.

Laqueur, Thomas W. Making Sex: Body and Gender from the Greeks to Freud. Cambridge, MA: Harvard UP, 1990.

Logan, Peter Melville. Nerves and Narratives: A Cultural History of Hysteria in Nineteenth-Century British Prose. Berkeley, CA: U of California P, 1997.

McWilliam, Rohan. 'What Is Interdisciplinary about Victorian History Today?' 19: Interdisciplinary Studies in the Long Nineteenth Century 1 (2005): 1-29. 10 August $2007<$ http:// www.19.bbk.ac.uk/>.

Marland, Hilary. Dangerous Motherhood: Insanity and Childbirth in Victorian Britain. New York, NY: Palgrave Macmillan, 2004.

Poovey, Mary. "'Scenes of an Indelicate Character": The Medical "Treatment" of Victorian Women'. Representations 14 (1986): 137-68.

- Uneven Developments: The Ideological Work of Gender in Mid-Victorian England. Chicago, IL: U of Chicago P, 1988.

ProQuest Digital Dissertations. ProQuest Information and Learning, 2007. 10 August 2007 $<$ http://collections.chadwyck.com>. 
Rothfield, Lawrence. Vital Signs: Medical Realism in Nineteenth-Century Fiction. Princeton, NJ: Princeton UP, 1992.

Rousseau, G. S. 'Literature and Medicine: The State of the Field'. Isis 72.3 (1981): 406-24.

Rylance, Rick. Victorian Psychology and British Culture, 1850-1880. Oxford: Oxford UP, 2000.

Small, Helen. Love's Madness: Medicine, the Novel, and Female Insanity, 1800-1865. Oxford: Clarendon, 1996.

Smith, Andrew. Victorian Demons: Medicine, Masculinity, and the Gothic at the Fin-de-Siècle. Manchester: Manchester UP, 2004.

Stoddard Holmes, Martha. Fictions of Affliction: Physical Disability in Victorian Culture. Corporealities. Ann Arbor, MI: U of Michigan P, 2004.

Suzuki, Akihito. Madness at Home: The Psychiatrist, the Patient, and the Family in England, 18201860. Berkeley, CA: U of California P, 2006.

Swenson, Kristine. Medical Women and Victorian Fiction. Columbia, MI: U of Missouri P, 2005.

Thompson, E. P. The Making of the English Working Class. London: Gollancz, 1963.

- William Morris, Romantic to Revolutionary. London: Lawrence, 1955.

Torgerson, Beth E. Reading the Brontë Body: Disease, Desire, and the Constraints of Culture. New York, NY: Palgrave Macmillan, 2005.

Vrettos, Athena. Somatic Fictions: Imagining Illness in Victorian Culture. Stanford, CA: Stanford UP, 1995. 